\title{
Medievalista
}

Online

$20 \mid 2016$

Número 20

\section{Geografías imperfectas: linaje y poder en la obra de Luís Krus}

Imperfect geographies: lineage and power in the work of Luís Krus

\section{Arsenio Dacosta}

\section{(2) OpenEdition}

1 Journals

\section{Edição electrónica}

URL: http://journals.openedition.org/medievalista/1167

DOI: 10.4000/medievalista.1167

ISSN: 1646-740X

\section{Editora}

Instituto de Estudos Medievais - FCSH-UNL

\section{Refêrencia eletrónica}

Arsenio Dacosta, "Geografías imperfectas: linaje y poder en la obra de Luís Krus », Medievalista [Online], 20 | 2016, posto online no dia 01 dezembro 2016, consultado o 23 setembro 2020. URL : http://journals.openedition.org/medievalista/1167 ; DOI : https://doi.org/10.4000/medievalista.1167

Mediavalista está licenciado com uma Licença Creative Commons - Atribuição-NãoComercial 4.0 Internacional. 
Título / Title: Geografías imperfectas: linaje y poder en la obra de Luís Krus / Imperfect geographies: lineage and power in the work of Luís Krus

Autor(es) / Author(s): Arsenio Dacosta

Universidade / University: Universidad de Salamanca

Faculdade e Departamento / Unidade de Investigação - Faculty and Department /

Research Center: Psicología Social y Antropología

Código Postal / Postcode: $\mathbf{3 7 0 0 7}$

Cidade / City: Salamanca

País / Country: España

Email: adacosta@zamora.uned.es

Fonte: Medievalista [Em linha]. Direc. Bernardo Vasconcelos e Sousa. Lisboa: IEM.

Disponível em:

http://www2.fcsh.unl.pt/iem/medievalista/MEDIEVALISTA20/dacosta2002.html

ISSN: 1646-740X

Data do texto: 5 de Outubro de 2015 


\title{
Geografías imperfectas : linaje y poder en la obra de Luís Krus / Imperfect geographies : lineage and power in the work of Luís Krus
}

\author{
Arsenio Dacosta
}

\section{Linaje e imaginario nobiliario}

En este trabajo ${ }^{1}$ pretendo repasar algunos conceptos y motivos queridos para Luís Krus, particularmente el de linaje y el de imaginario nobiliario, y lo haré a partir de algunos textos que él analizó con exhaustividad ${ }^{2}$. Recuérdese que en su tesis ${ }^{3}$ planteó algo tan novedoso como la concepción nobiliaria del espacio ibérico, precisamente en los livros de linhagens, tanto en lo que se refiere a la materialidad de las geografías señoriales como, sobre todo, al mundo de las representaciones del aludido imaginario nobiliario. Según Luís Krus, el Livro Velho se correspondería con "a visão monástico-senhorial de um Portugal ibérico e rural"4. En cambio, el Livro do Deão ponía en valor "a revelação

\footnotetext{
${ }^{1}$ Forma parte de los resultados del proyecto de investigación De la Lucha de Bandos a la hidalguía universal: transformaciones sociales, políticas e ideológicas en el País Vasco (siglos XIV y XV) financiado por el Ministerio de Economía y Competitividad (HAR2013-44093-P), e integrado en las actividades del Grupo de Investigación del Gobierno Vasco Sociedad, poder y cultura (IT-600-13). Es una versión ligeramente más amplia que la ponencia impartida en el marco del Colóquio Internacional Poder, Mitos e Memórias na Sociedade Medieval: Contributos de Luís Krus, organizado por el Instituto de Estudos Medievais de la Universidade Nova de Lisboa celebrado en Lisboa los días 1 y 2 de octubre de 2015.

${ }^{2}$ Una sintética pero completa reseña sobre la obra de Luís Krus en: SOUSA, Bernardo Vasconcelos e; BECEIRO PITA, Isabel - "Luís Krus (1954-2005). In memoriam". Hispania. Revista Española de Historia, n. 222 (2006), pp. 321-324. Una relación exhaustiva de toda su obra científica en ANDRADE, Amélia Aguiar et alii. - "Bibliografia de Luís Krus". in KRUS, Luís - A construção do passado medieval. Textos Inéditos e Publicados. Lisboa: Instituto de Estudos Medievais, 2011, pp. 309-326.

${ }^{3}$ La tesis doctoral de Luís Krus dispone de dos volúmenes y puede consultarse en la biblioteca Mário Sottomayor Cardia, al igual que los materiales de su biblioteca personal. Citaré este trabajo por su edición homónima: KRUS, Luís - A concepção nobiárquica do espaço ibérico (1280-1380). Lisboa: Fundação Calouste Gulbenkian/JNICT, 1994.

${ }^{4}$ KRUS, Luís - A concepção nobiliárquica..., p. 57 ss.
} 


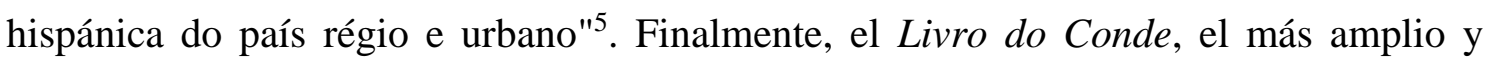
complejo de todos, implicaría "a teorização do destino hispânico"6.

Antes de proseguir convendría detenerse brevemente en el concepto de linaje nobiliario. Como ya señaló hace tiempo el profesor José Mattoso, en el ámbito del imaginario medieval, hay un espacio no pequeño entre las ideas y el terreno de la práctica ${ }^{7}$. Esto afecta de forma particular a la noción de linaje. Los medievalistas sabemos que dicha noción abarca realidades muy distintas y nada uniformes en la plena y baja Edad Media. Como bien recuerda Bernardo Vasconcelos e Sousa, en los livros de linhagens se aprecia esa clara tendencia hacia la filiación unilineal (masculina) y una jerarquización vertical de las relaciones sociales. Sin embargo, también constatamos, incluso a finales del siglo XIV, la existencia de prácticas de sucesión y herencia bilaterales y de unos vínculos linajísticos muy amplios donde el elemento central de cohesión es la asunción de un antepasado masculino común ${ }^{8}$. Este fetichismo del antepasado, generalmente el fundador epónimo del linaje, es el que planea en la definición de lo que Luís Krus denominaba família noble. No es lugar para entrar en la categorización conceptual de linaje toda vez que no existe consenso entre los medievalistas y tampoco entre los antropólogos ${ }^{9}$. Está por trazar la genealogía del concepto y, más aún, la transmisión del vocablo en los testimonios medievales. Como ha destacado recientemente el profesor José Carlos Ribeiro Miranda, en el ámbito galaico-portugués la difusión del concepto de linaje es estrictamente paralela al caso navarro, castellano y catalán ${ }^{10}$. Más allá del fin legitimador del Liber Regum y después de la historiografía alfonsí para sus respectivas dinastías regias, el desarrollo social del concepto tiene uno de sus espacios en la

\footnotetext{
${ }^{5}$ KRUS, Luís - A concepção nobiliárquica..., p. 71 ss.

${ }^{6}$ KRUS, Luís - A concepção nobiliárquica..., p. 113 ss.

${ }^{7}$ MATTOSO, José - "Da teoría à prática: o mundo das ideias no principio do século XIV". in Naquele Tempo. Ensaios de História Medieval. Lisboa: Temas e Debates / Círculo de Leitores, 2009, pp. 127-154.

${ }^{8}$ SOUSA, Bernardo Vasconcelos e - "Linhagem e identidade social na nobreza medieval portuguesa (séculos XIII-XIV)". Hispania. Revista Española de Historia, n. 227 (2007), pp. 881-898.

${ }^{9}$ Sobre el uso del concepto en el medievalismo francés del pasado siglo, véase GOODY, Jack - La evolución de la familia y del matrimonio en Europa. Barcelona: Herder, 1986 [1983], apéndice 1. Para el segundo asunto: KUPER, Adam - "Descent theory". in The Reinvention of Primitive Society: Transformations of A Myth. Londres: Routledge, 2005, pp. 163-178.

${ }^{10}$ MIRANDA, José Carlos Ribeiro - "O argumento da linhagem na literatura ibérica do séc. XIII". $e$ Spania. Revue électronique d'études hispaniques médiévales. [En línea]. N. 11 (2011). Disponible en https://e-spania.revues.org/20347?lang=es. Un análisis complementario desde una perspectiva crítica en DACOSTA, Arsenio - "De la anomalía a lo extraordinario: nobleza, linaje y escritura genealógica en Castilla (siglos XIII-XIV)". Hispania. Revista española de Historia, Vol. 75, n. 251 (2015), pp. 617-640.
} 
literatura trovadoresca ${ }^{11}$ - con un sentido sincrónico - y sobre todo en los livros de linhagens, donde el linaje se materializa como realidad social y autoimagen.

Recientemente - y aquí aprecio en mi obra la influencia de Luís Krus - me he preguntado si esas ideas sobre el linaje y la nobleza, aunque formuladas por autores concretos - incluyo aquí a los refundidores y copistas -, pueden seguir siendo abordadas como una suerte de "macrotexto" ${ }^{12}$. Creo imposible, incluso para la escala demográfica de un reino como Portugal, interpretar que estas ideas identifiquen a un estrato uniforme. La nobleza medieval se caracteriza por su diversidad y, sobre todo, por la pulsión jerárquica y competitiva que implica la exclusiva particularidad de cada linaje. Esto es lo que modula, en última instancia, que cada narrativa conservada obedezca a estrategias discursivas particulares. Para los livros de linhagens Luís Krus destacó que, a pesar de su imagen de conjunto, el objetivo de cada narrativa es subrayar el propio linaje en oposición al ajeno, aunque existan nexos reticulares entre unos y otros como demanda la lógica exogámica de la alianza. En este sentido, la idea de un "macrotexto" nobiliario quizá sea más fértil si se formula en términos de "pluralidad de hebras macronarrativas", en expresión de Donald Maddox ${ }^{13}$.

Luís Krus asumía esta doble perspectiva, pero con un sesgo que iba más allá de la histoire des mentalités. Dicho sesgo, implícitamente, liga la obra de Luís Krus con los paradigmas de la antropología interpretativa y antes que ella, con Max Weber. Clifford Geertz, referencia ineludible de la antropología actual, se sentía deudor de este último cuando definía al hombre como "un animal inserto en tramas de significación que él mismo ha tejido"14. En su tesis doctoral y en muchos de sus penetrantes artículos Luís Krus está próximo a esta conceptualización de la cultura, sin conocerla, al tiempo que ejerce esa "descripción densa" geertziana que, como el resto de discípulos del profesor

${ }^{11}$ Un breve análisis de conjunto en relación precisamente a los livros de linhagens en: OLIVEIRA, António Resende de - "A Cultura da Nobreza (sécs. XII-XIV) Balanço sem perspectivas". Medievalista [En línea]. N. 3 (2007).

Disponible en: http://www2.fcsh.unl.pt/iem/medievalista/MEDIEVALISTA3/index.htm

12 DACOSTA, Arsenio - "A propósito de un aparente silencio: la memoria genealógica escrita de la nobleza peninsular en la baja Edad Media". Tiempos Modernos. Revista electrónica de Historia Moderna, n. 31 (2016), en prensa.

${ }^{13}$ MADDOX, Donald - "Notes Toward a More Comprehensive Approach to Medieval Literary Cycles". in BESAMUSCA, B. et alli (eds.) - Cyclification: the Development of Narrative Cycles in the Chansons de Geste and the Arthurian Romances. Amsterdam: Norh Holland, 1994, p. 106.

${ }^{14}$ GEERTZ, Clifford - La interpretación de las culturas. Barcelona: Gedisa, 1987 [1973], p. 20. 
José Mattoso, ha sido una marca de escuela en la mejor tradición del medievalismo europeo. Ponerse en la piel del nativo, aquí el fidalgo portugués, está en el espíritu y en la letra de su obra, sin dejar de lado la sana distancia y su talento como observador de las experiencias ajenas.

He tratado de encontrar aquí un enfoque que hubiera sido del gusto de Luís Krus, aunque sin duda lo ejecutaré con tosquedad y menos intuición. No las necesito: como bien reza el título de la exposición que acompaña a este coloquio homenaje, dicho en palabras de Bernard de Chartres, nos esse quasi nanos, gigantium humeris incidentes ${ }^{15}$. Cuando leí su tesis doctoral no reparé en que Luís Krus había encabezado la misma con tres maravillosas citas literarias. Me serviré de ellas como pretexto, como procede en un homenaje como el presente, para esbozar tres ejemplos de "geografías imperfectas". Evito categorizarlas de "geografías imaginarias", concepto que está teniendo cierto éxito de la mano de la historia social de la cartografía ${ }^{16}$ y de propuestas neoestructuralistas acerca de la "antropología del imaginario"17. Mi perspectiva aquí es más bien semiótica, tomada de Umberto $\mathrm{Eco}^{18}$, para tratar de explorar el sentido social de estas construcciones. Dejaré de lado el mundo de lo sobrenatural y espiritual, así como el espacio de la utopía, muy presentes en cierto tipo de literatura medieval ${ }^{19}$, aunque no centrales en los testimonios de lo que podemos denominar escritura nobiliaria. Me

\footnotetext{
${ }^{15}$ La cita la transmitió su discípulo Juan de Salisbury en su Metalogicus, III, 4.

${ }^{16}$ Un ejemplo en MITCHELL, William J. T. (ed.) - Landscape and Power. Chicago: Chicago University Press, 2002 [1994], donde se incluyen trabajos de Edward Said y Michael Taussig. Tempranamente Luís KRUS también abordó esta perspectiva en algunas fichas catalográficas y en "A representaçao do mundo". in MATTOSO, José (coord.) - Os Descobrimentos Portugueses e a Europa do Renascimento. Lisboa: Impresa Nacional da Casa da Moeda, 1983, pp. 239-293.

${ }^{17}$ WUNENBURGER, Jean-Jacques - L'imaginaire. París: Presses Univeristaires de France, 2003, quien renueva la perspectiva de DURANT, Gilbert - Les Structures anthropologiques de l'imaginaire. París: Presses Univeristaires de France, 1960. Esta perspectiva fue fértilmente abordada por el medievalismo francés de la mano de Georges Duby, Jacques Le Goff y Jean-Claude Schmitt.

${ }^{18}$ El concepto ya estaba presente en ECO, Umberto - La ricerca della lingua perfetta nella cultura europea. Bari: Laterza, 1993, y es desarrollado en ECO, Umberto - Tra menzogna e ironía. Milán: Bompiani, 1998.

${ }^{19}$ Para lo primero, remito a DÍAZ Y DÍAZ, Manuel C. - Visiones del Más Allá en Galicia durante la alta Edad Media. Santiago de Compostela: Bibliófilos Gallegos, 1985, reseñado por Luís KRUS en Ler História, n. 8 (1986), pp. 121-122, y a otro autor que influyó en Krus: LE GOFF, Jacques - L'ímaginaire médiéval. Essais. París: Gallimard, 2013 [1991]. Otro ejemplo de esta perspectiva es el artículo: RUFFINATTO, Aldo - "Historia de ríos y bosques impuros (Berceo. Vida de Santo Domingo de Silos, v. 223d)". in Sobre textos y mundos. Ensayos de Filología y Semiótica Hispánicas. Murcia: Universidad de Murcia, 1989, pp. 15-34. Respecto del segundo tipo de literatura, véase un magnífico libro colectivo coordinado por Martín ALVIRA y Jorge DÍAZ - Medievo utópico. Sueños, ideales y utopías en el imaginario medieval. Madrid: Sílex, 2011.
} 
fijaré, pues, en tres espacios, tres geografías esenciales en el imaginario nobiliario y, también, en su materialidad, entresacados del Livro del conde Pedro de Barcelos.

\section{El solar. La identificación metafórica - y material - del primogénito}

La primera de las aludidas citas seleccionadas por Luís Krus es el conocido poema Esperando a los bárbaros de Constantin Kavafis ${ }^{20}$. En él se pueden leer estos versos: "Algunos han venido de las fronteras / y [han] contado que los bárbaros no existen". En no pocos fragmentos narrativos de los livros de linhagens, hallaremos indicios de esa verdad: la idea de la otredad se confunde en un juego de espejos que siempre devuelve la imagen de quien lo construye. Luís Krus lo abordó en varias ocasiones, como cuando analizó el relato del conde don Monido, godo llegado de Italia a las costas gallegas, y fundador de los Trava $^{21}$. Como le ocurre a Otger Cataló, el fundador legendario y epónimo de Cataluña, don Monido va acompañado de un puñado de caballeros que, a la postre, serán los fundadores de los primeros linajes de la tierra ${ }^{22}$. La conexión con las narrativas sobre la Casa de Haro es directa, pero no me detendré en el sugerente imaginario marítimo ${ }^{23}$ de Froom "d’ Ingraterra"24, sino en otro motivo del denominado Ciclo de Vizcaya, el bautizado por Alexandre Herculano como de la Dama Pé-de-Cabra en un conocido relato romántico fechado en $1843^{25}$.

\footnotetext{
${ }^{20}$ En traducción al francés de la no menos brillante Marguerite Yourcenar (KRUS, Luís - A concepção nobiliárquica..., p. 13).

${ }^{21}$ Analizado por Luís Krus, además de en su tesis, en dos artículos: "Tempo de Godos e Tempo de Mouros: as memórias da Reconquista" (1986-1987) y "As origens lendárias dos condes de Trastâmara" (1992), reeditados ambos en KRUS, Luís - A construção do passado medieval..., pp. 93-114 y pp. 181188.

${ }^{22}$ Una perspectiva de conjunto en DACOSTA, Arsenio - "La memoria de los antepasados: los relatos nobiliarios de origen en la Península Ibérica". in Discurso, memoria y representación. La nobleza peninsular en la Baja Edad Media. XLV Semana de Estudios Medievales de Estella. Pamplona: Gobierno de Navarra, 2016 (en prensa).

${ }^{23}$ Un trabajo de referencia al respecto es el de MATTOSO, José - "O imáginario marítimo medieval". in Naquele Tempo. Ensaios de História Medieval. Lisboa: Temas e Debates / Círculo de Leitores, 2009 [1998], pp. 223-236; publicado en paralelo al estudio de Luís Krus titulado: "O imaginário português e os medos do mar". in A descoberta do homem e do mundo. São Paulo: Ministério da Cultura / Fundação Nacional de Arte / Companhia das Letras, 1998, pp. 95-105. He abordado recientemente la cuestión de los viajes marítimos en otras narrativas nobiliarias medievales de fundación en "La memoria de los antepasados: los relatos nobiliarios de origen en la Península Ibérica".

${ }^{24}$ BARCELOS, Conde D. Pedro de - Livro de linhagens, IX A 1 (in Portugaliae Monumenta Historica [...]. Nova série, vol. II/1. Ed. José Mattoso. Lisboa: Academia das Ciências, 1980, p. 137). Sobre el Ciclo de Vizcaya, véase PRIETO LASA, José Ramón - Las leyendas de los señores de Vizcaya y la tradición melusiniana. Madrid: Fundación Ramón Menéndez Pidal, 1995.

${ }^{25}$ Publicado originalmente en HERCULANO, Alexandre - "A Dama Pé-de-Cabra". O Panorama n. 88/29 (1843), pp. 279-280 y reeditado numerosas veces desde 1851 en HERCULANO, Alexandre - Lendas $e$ narrativas. Lisboa: Impresa Nacional/Viúva Bertrand e Filhos, 1865, tomo II, pp. 7-15.
} 
Como a Alexandre Herculano, a Luís Krus le fascinó esta leyenda nobiliaria. Son conocidos los análisis de nuestro homenajeado: estas y otras melusinas representan un mundo oscuro y salvaje $\mathrm{y}$, al mismo tiempo, fértil y necesario ${ }^{26}$. Las hadas son portadoras de bienes y protectoras del linaje y sólo al final de la Edad Media se introduce la idea de que su naturaleza es diabólica, como ocurre con el tardío relato de fundación del linaje castellano de Manrique ${ }^{27}$. El indefinido monte - el mar en el caso de doña Marinha ${ }^{28}$ - es el reino del hada, mientras que su enamorado, el noble cazador, solo parece señorear plenamente entre los muros de su palacio. Es aquí, en el palacio, donde se produce el clímax de la narración, el momento de la ruptura del tabú.

Lo que me interesa destacar hoy no es ese tabú, sino la escena que lo precede: "quando comiam de suum dom Diego Lopez e sa molher, asseentava el a par de si o filho, e ela asseentava a par de si a filha da outra parte"29. Luís Krus ya intuyó en este pasaje la explícita tensión que se produce en el seno del linaje entre dos sistemas de filiación aparentemente irreconciliables: el agnático y el cognaticio ${ }^{30}$. El asunto parece más complejo, y nos lleva a la correspondencia directa, no metafórica, entre los símbolos y el sentido social de la primogenitura ligada al patrimonio del linaje. Diego López de Haro arranca a su heredero varón de las garras de su enfurecida hada. En última instancia, esto le permite al señor organizar el liderazgo del linaje evitando los conflictos en el proceso de reproducción social del mismo.

\footnotetext{
${ }^{26}$ Es la perspectiva adoptada por LE GOFF, Jacques - "Mélusine maternelle et défricheuse. Le dossier médiéval". Annales. Économies, Sociétés, Civilisations, n. 26/3-4 (1971), pp. 587-603; y también por Luís KRUS en sus dos artículos dedicados a la Dama vizcaína: "A morte das fadas: a lenda genealógica da Dama do Pé de Cabra" (1985) y "Uma variante peninsular do mito de Melusina: a origem dos Haros no Livro de Linhagens do Conde de Barcelos" (1994), algo más que una versión del anterior. Existe una reciente traducción al español de ambos trabajos en DACOSTA, Arsenio; PRIETO LASA, José Ramón; DÍAZ DE DURANA, José Ramón (eds.) - La conciencia de los antepasados. La construcción de la memoria de la nobleza en la baja Edad Media. Madrid: Sílex, 2014, pp. 17-42 y pp. 43-86.

${ }^{27}$ Para esta narrativa, véanse: RUCQUOI, Adeline - "Le diable et les Manrique". Razo, n. 8 (1988), pp. 103-111; y BECEIRO PITA, Isabel - "La conciencia de los antepasados y la gloria del linaje en la Castilla bajomedieval". in REYNA PASTOR (ed.) - Relaciones de poder, de producción y parentesco en la Edad Media y Moderna. Aproximación a su estudio. Madrid: C.S.I.C., 1990, p. 336; y DACOSTA, Arsenio - "La memoria de los antepasados: los relatos nobiliarios de origen en la Península Ibérica".

${ }^{28}$ En la estela de los trabajos de Luís Krus, véase: CARDIGOS, Isabel - "Dona Marinha: Une Mélusine Portugaise". in DUBOIS, Claude-Gilbert (org.) - L'Imaginaire de la Nation. Burdeos: Presses Universitaires de Bordeaux, 1991, pp. 185-192.

${ }^{29}$ BARCELOS, Conde D. Pedro de - Livro de linhagens, IX A 4 (ed. cit., vol. II/1, p. 139).

${ }^{30}$ KRUS, Luís - "Uma variante peninsular...", p. 161 ss.
} 
El solar, de hecho, es el elemento central en la sociología del parentesco y en la concepción linajística del poder. Su centralidad en la vida social y en el ámbito del prestigio es abrumadora, pero también en el imaginario nobiliario. El solar es el espacio de sociabilidad primaria, lugar de refugio y alimentación. El solar está ligado, además, al enterramiento, estableciendo así un punto de conexión principal entre la memoria familiar y el Más Allá. El solar da nombre al linaje que, más tarde, se simbolizará en unas armas heráldicas. Por último, y en los livros de linhagens es muy expresivo, el solar es el espacio primigenio, el lugar donde el fundador del linaje se asentó y multiplicó. Es el centro de una geografía que debe reproducirse cíclicamente, generación tras generación. Tal y como ha señalado José Augusto Sottomayor Pizarro lo esencial en la lógica linajística no es tanto la determinación de la primogenitura como la idea de continuidad ${ }^{31}$.

\section{La corte: paradigma cidiano y estrategias genealógicas}

La segunda cita con la que abría Luís Krus la edición de su tesis estaba tomada del Poema del Mío Cid, donde al anónimo poeta le faltan líneas para describir la geografía de sus conquistas ${ }^{32}$. El Cid, perfecto noble y paradigma anticortesano, configura el modelo con el que Pedro Afonso pretende "meter amor e amizade entre os nobres fidallgos da Espanha" ${ }^{33}$. No hablaré del Cid sino de un personaje que en todo se le asemeja y que, de facto, comparte tiempo y espacio, aunque sean imaginarios. La narrativa sobre Rodrigo Froiaz de Trastâmara contiene elementos que le ligan al arquetipo cidiano, como la tensión entre monarquía y nobleza, o el paradigma del buen consejero mal atendido por su rey ${ }^{34}$. El relato de Rodrigo Froiaz o Bom advierte de los riesgos de la herencia cuando critica la partición del patrimonio de Fernando I de Castilla, que va contra la lógica linajística de la primogenitura. Esta lógica, obviamente, no es la del siglo XI, sino la del XIV, momento en el que esta historia es narrada en el

\footnotetext{
31 SOTTOMAYOR PIZARRO, José Augusto - Linhagens medievais portuguesas. Genealogias e Estratégias (1279-1325). Oporto: Universidade do Porto, 1997, vol. I, p. 116.

${ }^{32}$ KRUS, Luís - A concepção nobiliárquica..., p. 14.

${ }^{33}$ BARCELOS, Conde D. Pedro de - Livro de linhagens, prólogo, 2 (ed. cit., vol. II/1, p. 55).

${ }^{34}$ Sobre esto, véase DEL RÍO, María Gimena - "Novela y nobleza: reelaboraciones de la figura cidiana en el siglo XIV (los Rodrigos del Livro de linhagens do Conde Dom Pedro)". in Fundación para la Historia de España. VII. 2004-2005. Buenos Aires: Embajada de España, 2005, pp. 41-50.
} 
Livro de linhagens ${ }^{35}$. El relato, bien conocido, nos habla de la segunda de las geografías imperfectas del imaginario nobiliario que me interesa destacar: la corte.

En esta narrativa, el rey desprecia el consilium de los ricos-hombres y se apoya en un privado cuya malicia es castigada por el héroe con la muerte. El palacio de esta narrativa es, de nuevo, un escenario imaginario. El resultado de la buena acción del héroe provoca su destierro, como le ocurre al Cid, en un viaje que conforma un espacio invertido al cortesano, aunque en su misma lógica itinerante. Por ello la corte de García es sustituida por la del rey de Francia. Aquí hallamos otro topos de las geografías imperfectas, en el sentido que emplea Umberto Eco, y que se manifiesta en el relato cuando el perdón y la súplica regia le llegan a Rodrigo Froiaz no a Francia sino "a Navarra". El noble regresa a la corte de su rey a prestar su auxilium, a presentar batalla a los castellanos. Rodrigo Froiaz lidera las huestes compuestas por los "boos fidalgos de Portugal", en un interesado anacronismo concretado en la referencia a la "terra de Portugal" identificada aquí con el núcleo del reino de don García. El resultado de la batalla entre castellanos y portugueses tiene, a pesar de la derrota castellana, un cierto aire fratricida e inútil. En la lógica ibérica de Pedro de Barcelos los nobles son los que sufren las malas decisiones de sus reyes a pesar de que son los primeros y verdaderos señores de la tierra. Estamos ante lo que mi buena amiga Isabel de Barros Dias definió como "As penas de Ícaro"36.

La continuación del relato expresa en boca de Rodrigo Froiaz una realidad geoestratégica: es mejor ir a la batalla contra Sancho II de Castilla que esperar una larga guerra de desgaste en la que Portugal - que no Galicia - tiene las de perder. La batalla es vencida de nuevo por los portugueses, incluyendo el apresamiento del rey castellano, pero el héroe queda irremediablemente herido. Rodrigo Froiaz manda llamar al rey hasta el indefinido lugar donde tiene preso al castellano. Tras un dramático parlamento,

\footnotetext{
${ }^{35}$ BARCELOS, Conde D. Pedro de - Livro de linhagens, XXI G 7 (completo en ed. cit., vol. II/1, pp. 224-229). Sobre el inmediato precedente arquetípico de este relato en la Primera Crónica General, véase PAREDES NÚÑEZ, Juan Salvador - "Ficción histórica y realidad literaria en los nobiliarios peninsulares: la historización mitológica". in La literatura en la historia y la historia en la literatura: in honorem Francisco Flores Arroyuelo. Murcia: Universidad, 2009, p. 286 ss.

${ }^{36}$ Título de una de las secciones de su magnífico DIAS, Isabel de Barros - Metamorfoses de Babel. A Historiografia ibérica (sécs. XIII-XIV): construções e estratégias textuais. Lisboa: Fundação Calouste Gulbenkian/FCT, 2003, pp. 119-356.
} 
incluyendo los "grandes sospiros e lagremas" del rey García, Rodrigo Froiaz muere haciendo entrega de su regia presa con un gesto igualmente simbólico: besando la mano de su rey y encomendando su alma al Altísimo ${ }^{37}$. La historia finaliza con la huida de Sancho II por una imprecisa "serra", huida en la que sólo se ve aliviado cuando le anuncian la proximidad del pendón verde del Cid.

El sentido de la narrativa es altamente prestigiante, y los enlaza con otras "estrategias genealógicas" como las de sus parientes los Lara castellanos ${ }^{38}$. La leyenda de los infantes de Lara, magnífica pieza literaria también recogida por Pedro de $\operatorname{Barcelos}^{39}$, no es menos potente que la narrativa sobre el pecho de los fijosdalgo recientemente estudiado por Francisco Bautista precisamente a partir de la Crónica de $1344^{40}$. En la primera hay una moralización sobre las virtudes del líder del linaje, el peso de la sangre noble y la trágica lógica de la venganza. En la segunda, los Lara operan como Rodrigo Froiaz o el Cid - grandes vasallos si tuvieran buenos señores - enfrentándose a sus reyes en ese indefinido espacio cortesano. Narrativas que articulan discursos de aspiración política, incluyendo el más expreso y singular de todos ellos, el del "linaje maldito" que articula el Libro de las tres razones de don Juan Manuel ${ }^{41}$, estrictamente contemporáneo de Pedro de Barcelos. En esta construcción de discursos no bastará, como no le basta a los Trava-Trastâmara o a tantos otros linajes de la alta nobleza, reclamar en sus narrativas una estirpe regia. Esta aspiración dinástica es estrictamente prestigiante - salvo en don Juan Manuel - y está acotada por la lógica de alianzas de la familia regia y por una arena política en la que los nobles son solo una parte de los

\footnotetext{
${ }^{37}$ BARCELOS, Conde D. Pedro de - Livro de linhagens, XXI G 7 (ed. cit., vol. II/1, p. 228). Sobre el "don de las lágrimas" en la Edad Medía, véase MATTOSO, José - "A mística das emoções: o dom das lágrimas". in Naquele Tempo..., pp. 81-94.

${ }^{38}$ Un magnífico estudio sobre las narrativas de los Lara y los Maia en los livros de linhagens en: FERREIRA, Maria do Rosário - "A estratégia genealógica de D. Pedro, Conde de Barcelos, e as refundições do Livro de Linhagens". e-Spania. Revue interdisciplinaire d'études hispaniques médiévales et modernes. [En línea]. N. 11 (2011). Disponible en http://e-spania.revues.org/20273

${ }^{39}$ BARCELOS, Conde D. Pedro de - Livro de linhagens, X A 1-2 (ed. cit., vol. II/1, pp. 147-148). El motivo fue estudiado por MATTOSO, José - "Sangue e família no cantar dos infantes de Lara". in Estudos e ensaios em homenagem a Vitorino Magalhães Godinho. Lisboa: Livraria Sá Da Costa, 1988, pp. 207-216.

40 BAUTISTA, Francisco - "Narrativas nobiliarias en la historiografía alfonsí y postalfonsí". in DACOSTA, Arsenio; PRIETO LASA, José Ramón; DÍAZ DE DURANA, José Ramón (eds.) - La conciencia de los antepasados. La construcción de la nobleza en la Baja Edad Media. Madrid: Marcial Pons, 2014, pp. 110-116.

${ }^{41}$ Sobre esta cuestión, véase: ARIAS GUILLÉN, Fernando - "El linaje maldito de Alfonso X. Conflictos en torno a la legitimidad regia en Castilla (c. 1275-1390)". Vínculos de Historia, n. 1 (2012), pp. 147-163.
} 
actores en liza. Sin embargo, hemos visto que los nobles aspiran a que la corte sea un espacio privativo de encuentro y negociación entre el rey y sus más directos vasallos. Esta geografía no tanto imperfecta como imposible en el siglo XIV, se estaba entonces reelaborando bajo una nueva y potente idea: la de la caballería.

\section{La frontera: más allá del sentido prático de la nobleza}

La tercera y última cita fue tomada por Luís Krus del Livro del caballero Zifar, otra obra cumbre de la literatura medieval, aludiendo a la poética del viaje ${ }^{42}$. Ello me permite entrar en la última de las geografías imperfectas: la frontera ${ }^{43}$. No habré ocuparme de la frontera como geografía de la confrontación. Para el noble peninsular, la frontera es un espacio propio por determinación funcional, pero ajeno a él por circunstancias políticas. Las fronteras interiores, como las marcadas por el tradicional centralismo de la monarquía portuguesa, deja libre de señoríos el espacio al sur del Tajo. Las fronteras con lo que será la Corona de Castilla ${ }^{44}$, no serán verdaderamente osmóticas para la nobleza hasta el periodo fernandino ${ }^{45}$. Las fronteras con el Islam han quedado resueltas para Portugal prácticamente bajo el reinado del primero de sus monarcas, Afonso Henriques, y plenamente culminadas mediado el siglo XIII de la mano de Sancho II y Afonso III. A este horizonte, a este espacio, habré de referirme. La pluma de Pedro Afonso de Barcelos y sus refundidores se entrelazan con los sucesos de su tiempo, particularmente con la batalla del Salado, donde la caballería portuguesa volvía a encabezar la lucha contra el Islam, armada con la reliquia de la Vera $\mathrm{Cruz}^{46}$.

¿Qué frontera es, pues, a la que se refiere el último de los tres livros de linhagens portugueses? La conquista de Toledo, marco referencial en el imaginario de Pedro de Barcelos, quedaba muy lejos. Lisboa había sido una gran empresa, como la conquista de Sevilla, pero a estas alturas ambas ya quedaban lejos. Además, el protagonismo en estas

\footnotetext{
${ }^{42}$ KRUS, Luís - A concepção nobiliárquica..., p. 14.

${ }^{43}$ Algo que también abordó Luís KRUS en: "O olhar do guerreiro da Reconquista sobre a paisagem". $O$ Estudo da História, n. 3-4 (1987), pp. 7-10.

${ }^{44}$ Para esto remito a: VENTURA, Leontina - "A fronteira luso-castelhana na Idade Média". Revista da Faculdade de Letras. Historia, n. 15/1 (1998), pp. 25-52; y KRUS, Luís - "A moralização medieval da fronteira luso-castelhana". in Em louvor da linguagem. Homenagem a M. Leonor Carvalhão Buescu. Lisboa: Edições Colibri, 2003, pp. 205-210.

${ }^{45}$ Una buena visión de síntesis en: SOTTOMAYOR PIZARRO, José Augusto - "De e para Portugal. A circulação de nobres na Hispânia medieval (séculos XII a XV)". Anuario de Estudios Medievales, n. 40/1 (2010), pp. 889-924.

${ }^{46}$ BARCELOS, Conde D. Pedro de - Livro de linhagens, XXI G 14-15 (ed. cit., vol. II/1, p. 245).
} 
victorias no era trofeo exclusivo de la nobleza al tener que compartirlo con las milicias urbanas y, sobre todo, con las dinastías fundadoras o unificadoras de los reinos de Portugal y Castilla. La participación de los portugueses en la batalla del Salado a quien beneficia narrativamente es, básicamente, al prior Alfonso Gonçalves Pereira y a su linaje, pero esto obedece a la pluma del refundidor. Precisamente fue Luís Krus quien destacó este aspecto y el nada inocente relato sobre el prior hospitalario y su formación en Tierra Santa, a la que viajó "com cavaleiros e outras gentes muitas"47. El relato recuerda el aludido viaje que, en dirección inversa pero con idénticos objetivos, había protagonizado don Monido, ancestro de los Trastâmara. En cierta forma este relato recuerda al del ancestro fundador de los Babilão, Rui Gonçalves, que, como el anterior, parece fruto de la refundición operada en la década de 1380 en el Livro do Conde. El relato sobre Rui Gonçalves es bien conocido y nos habla de un viaje a "terra de Babilonia a fazer suas cavalarias pera gaanhar algo" que parece tener poco o nada de histórico ${ }^{48}$.

La referencia a esas "cavalarias" es demasiado expresa para no incidir en el modelo caballeresco, plenamente difundido ya a mediados del siglo XIV. Me interesa, como a Luís Krus, la lógica social de estas narrativas ${ }^{49}$, muy diferente como veremos de la de algunos modelos literarios. Tomemos la aludida cita al Libro del caballero Zifar, contemporáneo a las obras genealógicas de Pedro de Barcelos. En esta conocida anécdota el caballero Zifar vence a un "señor de la hueste" que, a pesar de ello, le ofrece "grandes mercedes". El señor quiere conocer el origen e identidad de Zifar pero éste no renuncia a su objetivo: el viaje ${ }^{50}$.

\footnotetext{
${ }^{47}$ KRUS, Luís - A concepção nobiliárquica..., p. 140.

${ }^{48}$ Ya advirtió José Mattoso de lo improbable de que este personaje, identificable con un hidalgo miñoto de mediados del siglo XIII, corriera tal aventura en Tierra Santa, siendo factible en cambio su presencia en las campañas andaluzas de su tiempo (MATTOSO, José - "As fontes do Nobiliario do Conde D. Pedro". in A nobreza medieval portuguesa: a familia e o poder. Lisboa: Estampa, 1981, p. 59). Sobre la identificación de "Babilonia" en este y otros relatos bajomedievales, véase LADERO QUESADA, Miguel Ángel - "Portugueses en la frontera de Granada". En la España Medieval, n. 23 (2000), pp. 67-100, en especial, pp. 76-85.

${ }^{49}$ Para esta cuestión, remito a: SPIEGEL, Gabrielle - "History, historicism, and the social logic of the text in the Middle Ages". Speculum: A Journal of Medieval Studies, n. 65 (1990), pp. 59-86.

${ }^{50}$ RIQUER, Martín de - El caballero Zifar. Barcelona: Ariel, 1951, vol. I, p. 111.
} 
Si hay una narrativa linajística que tiene elementos comunes con la anterior esa es la de Rui Gonçalvez Babilom, una de las últimas recogidas en el Livro de linhagens ${ }^{51}$. Como Zifar, Babilom es admirado por su destreza guerrera y como aquel también es interrogado sobre su origen. El señor que promueve la lid le pregunta "se trazia carta de cavalaria". El fidalgo responde "que em sa terra nom preguntavam ao cavaleiro por carta de cavalaira, senom ao creligo por carta das ordees". La ofensa no es olvidada: cuando Babilom está a punto de rematar al notable le muestra irónico su arma: "Esta maça tragia eu como te servisse, e com esta te deservirei".

Las credenciales de los nobles ibéricos son las armas, a través de las cuales acceden al servicio del rey. Es aquí, en la lógica social de estos relatos, donde sus contemporáneos se reconocen, incluso en aquellos en los que el redactor introduce narrativas desprestigiantes ${ }^{52}$. Estas narrativas constituyen un relato diferencial del propio origen en su contexto de producción y difusión ${ }^{53}$ pero, en conjunto, también una autoimagen estamental ${ }^{54}$.

No es casual que el refundidor del Livro do Conde recrezca el capítulo ${ }^{55}$ dedicado al nuevo gran héroe luso, Álvaro Gonçalves, prior del Hospital, y que éste sea padre del Condestable Nuno Álvares, promotor a su vez de la "última refundição" de la Crónica Geral de Espanha de $1344^{56}$. Los Pereira, hacedores de reyes por la fuerza de la política y la sangre, serán en este relato los principales beneficiarios del patrimonio simbólico de los Trava y de los Maia, dos de los cinco linajes fundadores del reino ${ }^{57}$. No es casual

\footnotetext{
${ }^{51}$ BARCELOS, Conde D. Pedro de - Livro de linhagens, LXXII C 2 (ed. cit., vol. II/1, pp. 167-168).

52 Véase un sistemático análisis de caso en SOUSA, Bernardo Vasconcelos e - "Los Pimentel y la construcción de una memoria linajística". in DACOSTA; Arsenio; PRIETO, José Ramón; DÍAZ DE DURANA, José Ramón (eds.) - La conciencia de los antepasados..., pp. 175-200.

${ }^{53}$ Es la perspectiva en la que insiste KRUS, "Una variante peninsular...". in DACOSTA; Arsenio; PRIETO, José Ramón; DÍAZ DE DURANA, José Ramón (eds.) - La conciencia de los antepasados..., p. 23 ss.

${ }^{54}$ En esta perspectiva, véase DACOSTA, Arsenio - "De la conciencia del linaje a la defensa estamental. Acerca de algunas narrativas nobiliarias vascas". Medievalista [En línea]. N. 8 (2010). Disponible en http://www2.fcsh.unl.pt/iem/medievalista/MEDIEVALISTA8/dacosta8007.html

${ }^{55}$ BARCELOS, Conde D. Pedro de - Livro de linhagens, XXI G 14-15 (ed. cit., vol. II/1, pp. 238-257).

${ }^{56}$ COSTA, Paula Pinto; FONSECA, Luis Adão da - "A Historiografía". En Entre Portugal e a Galiza (sécs. XI a XVII). Um olhar peninsular sobre uma região histórica. Oporto: CEPESE/Fronteira do Caos, 2014, p. 418.

${ }^{57}$ Es significativo que en el Livro de linhagens la vida de Álvaro Gonçalves Pereira esté precedida de la de su suegro, Gonçalo Mendes da Maia; véase: BARCELOS, Conde D. Pedro de - Livro de linhagens, XXI G 6 (ed. cit., vol. II/1, pp. 219-224). Sobre esto, véase KRUS, Luís - "O discurso sobre o passado na
} 
que los Pereira sean, también, los defensores de esa nueva caballería como ha destacado recientemente Stéphane Boissellier ${ }^{58}$. Otro de estos linajes es el de Babilão que, como los anteriores o los Pimentel, tratará de hacerse con ese capital simbólico - en este caso el de los Maia - con la construcción de una imagen heroica de visos igualmente imaginarios, que no por ellos son ahistóricos.

\section{Conclusión: la construción social de la poética nobiliaria}

Las geografías por las que se mueven los personajes de las narrativas nobiliarias de los livros de linhagens son, como bien destacó Luís Krus, espacios concretos y, al mismo tiempo, concepciones abstractas. Se trata de espacios históricos, reales o imaginarios, que representan la autoimagen de un linaje o se articulan como parte de un potente discurso estamental. Son también lugares que cuentan para los compiladores de narrativas particulares, como son Pedro de Barcelos y sus refundidores, en sus recreaciones, sus estrategias desprestigiantes y sus maniobras de apropiación simbólica. Por ello, la aparente imperfección de estas geografías no lo es a la luz del proceso de escritura, de sus objetivos y de la eficacia narrativa de las mismas en los relatos nobiliarios ${ }^{59}$. Como ha expresado Maximiliano Soler, "estos pasajes priorizan el espacio concreto, habitado y recorrido por los nobles, el espacio como hecho" ${ }^{60}$. Luís Krus no sólo escribió sobre una geografía del poder, sino también de cómo la particular poética de la nobleza medieval debía interpretarse factualmente como una construcción social.

\footnotetext{
legitimação do senhorialismo português dos finais do século XIII". in A construção do passado medieval..., pp. 171-180.

58 BOISSELLIER, Stéphane - "Ideologia da guerra ou ideologia dos guerreiros? Mais algumas interpretações do relato da batalha do Salado (1340) no Livro de Linhagens do Conde Dom Pedro". Revista Diálogos Mediterrânicos, n. 7 (2014), pp. 84-103.

${ }^{59}$ La perspectiva de la construcción arquetípica de los héroes medievales la aborda para un caso similar: LARANJINHA, Ana Sofia - "L'Histoire contre le désordre du monde: Arthur et Charlemagne dans les Bienandanças e Fortunas de Lope García de Salazar". e-Spania. Revue électronique d'études hispaniques médiévales. [En línea]. N. 19 (2014). Disponible en http://e-spania.revues.org/23929

${ }^{60}$ SOLER, Maximiliano - "La configuración del espacio en la historiografía castellana bajomedieval: una microlectura". Estudios de Historia de España, n. 13 (2011), p. 147. La cursiva en el original de Soler.
} 


\section{COMO CITAR ESTE ARTIGO / HOW TO QUOTE THIS ARTICLE}

\section{Referência electrónica:}

DACOSTA, Arsenio - "Geografías imperfectas: linaje y poder en la obra de Luís Krus".

Medievalista [Em linha]. N. 20 (Julho - Dezembro 2016). [Consultado dd.mm.aaaa].

Disponível em

http://www2.fcsh.unl.pt/iem/medievalista/MEDIEVALISTA20/dacosta2002.html ISSN 1646-740X.

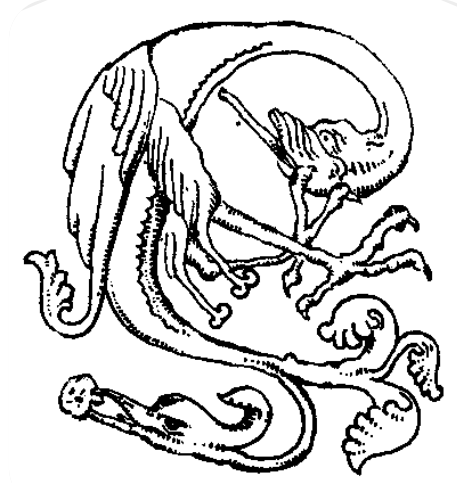

